\title{
Development of Mn(III)(Schiff Base) Complexes for the Catalyst of Olefin Oxygenation to Alcohols in the Presence of $\mathrm{NaBH}_{4}$
}

\author{
Nam Ho Lee, Jong Chul Byun, Jong Seok Baik, Chung-Hun Han, and Sung-bin Han \\ Department of Chemistry, (Thejt National Hniversity, Ara-1, (hein 690-756, Korea \\ Received M/OH $1+2002$
}

Key Words : Oxygenation. Mn(Schilf base) complex, Olelin Oxidation

Molecular oxygen would be the most desirable oxidant in organic synthesis in termis of costs and environmental considerations. Efforts have long been focused on the development of $\mathrm{O}_{2}$-mediated oxidation methods. ${ }^{\text {' We have }}$ reported previously the oxidative conversion of olefins to the alcohols. where molecular oxygen was used as the oxidant. In this process, we used a (salen) $\mathrm{Mn}$ (III)Cl complex 1 as the catalyst and sodium borohydride as the one-oxygen reducing agent. ${ }^{2}$ Even though this process was performed under mild conditions. only conjugated vinyl arene substrates were oxidized with high efficiency (Eq. 1). Other olefin substrates. for example non-conjugated or non-vinylic olefins, showed very low reactivity: Therefore, we decided to develop better oxidation catalysts, which could be applicable to the variety of simple olefins.

$$
\begin{aligned}
& \underset{R}{\operatorname{Ar}} \underset{R}{P}+\mathrm{O}_{2}(1 \mathrm{~atm})+(1.5-2.0) \mathrm{NaBH}_{4} \\
& \frac{\text { (salen)Mn(III) } 1}{\text { benzene/ethanol }} \underset{\mathrm{OH}}{\mathrm{Ar}} \underset{\mathrm{H}}{\mathrm{C}} \\
& (73-87 \%)
\end{aligned}
$$

For the screening of the cataly tic activity. we have synthesized several Mn(11I)-Scliff base ligand complexes. Tetradendate bis-salicylaldimine type ligands were prepared by the coupling of salicyl aldehy des and corresponding diamine compounds. The prepared Schiff base ligands were treated with manganese(ll) acetate followed by air oxidation to provide Mn(III)(Schiff base) complexes. "2 Eventually, three

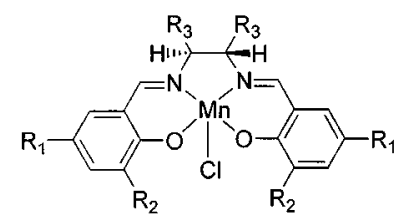

I $\mathrm{R}_{1}=\mathrm{H} \mathrm{R}_{2}=\mathrm{H} \mathrm{R} \mathrm{R}_{3}-\mathrm{R}_{3}=-\mathrm{CH}_{2} \mathrm{CH}_{2} \mathrm{CH}_{2} \mathrm{CH}_{2}-$ $2 \mathrm{R}_{1}=\mathrm{H} \mathrm{R} \mathrm{R}_{2}=\mathrm{H} \mathrm{R} \mathrm{R}_{3}=\mathrm{H}$

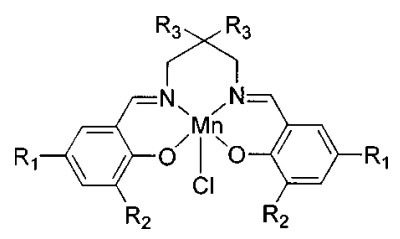

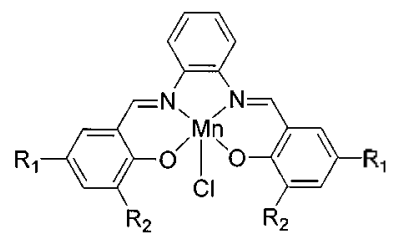

$3 \mathrm{R}_{1}=\mathrm{H} \mathrm{R}_{2}=\mathrm{H}$

$$
\begin{array}{llll}
4 \mathrm{R}_{1}=\mathrm{H} & \mathrm{R}_{2}-\mathrm{H} & \mathrm{R}_{3}-\mathrm{H} \\
5 \mathrm{R}_{1}=t-\mathrm{Bu} & \mathrm{R}_{2}=\mathrm{t}-\mathrm{Bu} \mathrm{R}_{3}-\mathrm{H} \\
6 \mathrm{R}_{1}=\mathrm{Cl} & \mathrm{R}_{1}=\mathrm{Il} & \mathrm{R}_{3}-\mathrm{H} \\
7 \mathrm{R}_{1}-\mathrm{H} & \mathrm{R}_{2}=\mathrm{H} & \mathrm{R}_{3}=\mathrm{Cl}_{3} \\
8 & \mathrm{R}_{1}=t-\mathrm{Bu} & \mathrm{R}_{2}=t-\mathrm{Bu} & \mathrm{R}_{3}=\mathrm{CH}_{3} \\
9 \mathrm{R}_{1}=\mathrm{Cl} & \mathrm{R}_{2}=\mathrm{H} & \mathrm{R}_{3} \quad \mathrm{CH}_{3}
\end{array}
$$

types of manganese(III) complexes were prepared. i.e. diaminoethane-derived Mn complexes (1. 2), diaminobenzene-derived $\mathrm{Mn}$ complex (3), and diaminopropane-derived Mn complexes (4-9).

The catalytic activity of the complexes was examined using trans-b-methylsty rene (10) and allyl benzene (11) as the model substrate (Table 1). The reaction was carried out using $5 \mathrm{~mol} \% \mathrm{Mn}$ complexes and 1.5 equiv. of $\mathrm{NaBH}_{4}$ under balloon pressure of $\mathrm{O}_{z}$ at room temperature. Previously: employing the (salen)Mn(III) complex 1 as the catalyst. the compounds 10 and 11 were oxidized in only $39 \%$ and $10 \%$ colnersion yield. respectively: When the Mn-salen complex 2 was tried as the catalyst. rather lower substrate conversion was observed (entry 2). Mn(lll)(salen)phenyl type complex 3 also gave lower reactivity (entry 3 ). However diaminopropane-derived $\mathrm{Mn}(\mathrm{III})$ complex $\boldsymbol{\psi}$ showed big improvement in the conversion yield. For example. using complex 4 . we colnerted olefins 10 and 11 in $86 \%$ and $38 \%$ yield. respectively (entry + ). Different types of related complexes were examined (entries 5-9). taking the complex 4 as the leading compound. From this screening. it was concluded that dimethyl-substituted complex analogue 7 has the best catalytic activity among the complexes in Table 1 . We observed, interestingly, that introduction of the bulky and electron-rich tert-butyl group, as shown in 5 and 8 . resulted in activity decrease. Another interesting observation was that electron poor Cl-substituted complexes. such as 6 and 9. showed comparable but no better catalytic activity over the simple complex 7. From the results in Table 1, we concluded that complex 7 is the best choice for a catalyst for this oxidation system. ${ }^{+}$The origin of the reactivity differences for these Mn(III)(Schiff Base) complexes is not clear at this point. It might be ascribed to their differences in electronic/ steric properties around the Mn metal or in their physical properties, such as solubility in the reaction system.

With the result in Table 1 at hand. we performed the oxidation with various type of olefin substrates. ${ }^{5}$ The results are summarized in Table 2. Non-conjugated viryl compound. allyl benzene, gave the corresponding alcohol in $61 \%$ isolated yield (entry l). This reaction was very regiospecific. giving only Markovnikov type hydration product. Conjugated internal olefin. trans- $\beta$-methylstyrene was also well oxidized in $72 \%$ yield (entry 2 ). This concersion was also regioselective: only the compound oxidized at the benzylic position was observed. Cis- $\beta$-methylstyrene was also oxidized 
Table 1. Screening of the Mn(III)( salen) type complexes for the oxidation catalyst using the substrates 10 and 11

\begin{tabular}{|c|c|c|c|}
\hline \multirow[b]{2}{*}{ Fintry } & \multirow{2}{*}{$\begin{array}{l}\text { Mn(III) } \\
\text { Complex }\end{array}$} & \multicolumn{2}{|c|}{ Conversion ( $\%)$} \\
\hline & & $\begin{array}{c}\mathrm{Ph} \rightleftharpoons \mathrm{CH}_{3} \\
10\end{array}$ & $\begin{array}{c}\mathrm{Ph} \sim \mathrm{A} \\
\mathbf{1 1}\end{array}$ \\
\hline 1 & $\mathbf{1}$ & 39 & 10 \\
\hline 2 & 2 & 5 & 1 \\
\hline 3 & 3 & 18 & 0 \\
\hline 4 & 4 & 86 & 38 \\
\hline 5 & 5 & 30 & 21 \\
\hline 6 & 6 & 95 & 58 \\
\hline 7 & 7 & 96 & 70 \\
\hline 8 & 8 & 13 & 12 \\
\hline 9 & 9 & 85 & 66 \\
\hline
\end{tabular}

"Reaction conditions: the substrate was treated with 1.5 equiv. $\mathrm{NaBH}+$ and $5 \mathrm{~mol} \% \mathrm{Mn}(\mathrm{II})$ complexes in the presence of $\mathrm{O}(1$ atm $)$ at it for 4 hrs. "Comersion was obtained by GC: analysis.

Table 2. Iixamples of oletin oxygenation reactions using the Mn(III) complex 7 as the calalys

lenzeneiethanol rt. 4 hrs

in about the same yield as troms substrate (entry 3). Cimantyl alcohol was converted to the corresponding alcohol in $65 \%$ yield, which shows that alcohol functionality rarely affects the reactivity (entry 4). Conjugated cyclic olefins, such as 1,2-dihydronaphthalene, indene, and dimethylehromene, were also good substrates for this oxidation procedure, providing the corresponding alcohols in $82 \%, 81 \%$ and $65 \%$ yicld, respectively (entries 5-7). Tertiary alcohol was also oblained from the tri-substiluted olefins. For example, phenyl dihydronaphthalene gave the alcohol in $70 \%$ yield (entry 8). But, $1-$ phenylcyelohexene showed poor conversion, leading 10 only $38 \%$ isolated yield. In this case, some starting material was left intact. Limonene was also subjected to the reaction condition (eniry 10). The major compound, isolated in $20 \%$ yicld, was identified to be tertiary alcohol resulting from the oxygenation on vinylic olefin over the electron-rich $\mathrm{Ir}^{\mathrm{i}}$ substituted one.

By screening Mn(III)(Schill Base) complexes, we have shown that onc of the complexes. 7 is a very good catalyst for the olelin oxygenation process. Complex 7 was found to be casy to handle due to its stability in moisture and ait. This process takes place under mild reaction conditions, ie. balloon pressure of oxygen and room temperalure. Further studies to expand the scope of this oxygenation process are in progress.

Acknowledgment. This work was supported by grant No. R02-2000-00075 from the Korca Science \& Engincering Foundation.

\section{References}

1. Simándi, 1. 1. Catalytic Activation of Dorrgen by Metal Complexes: Kluwer Academ ic Publishers: Boston. 1992.

2. I.ec, N. H.: Baik, J. S.: Han, S-B., Bull. Korean Chem. Soc, 1999. 20. 867. and references ciled therein.

3. Byun. J. C.: I Jan. C. II.: Lee. ‥ II.: Baik. I. S. Manuscript submitted for the publication.

4. Spectral data of the complex 7: Cicmental Analysis. Calcd for $\mathrm{C}_{14} \mathrm{H}_{211} \mathrm{~N}_{2} \mathrm{O}_{2} \mathrm{MnCl}: \mathrm{C}, 57.23 ; \mathrm{H}, 5.06: \mathrm{N}, 7.03$. Found: $\mathrm{C}, 57.20: \mathrm{H}$. 4.78: N. 7.09. IR (KBr, cm '): $2959(\mathrm{~m}) .2901$ (m). 1628 (s). 1606 (s). 1544 (s). 1469 (s). 1444 (s). 1303 (s). 1277 (s): UV (MeOH): $374 \mathrm{~nm}$.

5. Typical reaction condition is as follows: In a $50 \mathrm{~mL}$ two-neck round bottomed flask were placed mans- $\beta$-methylstyrene (1.0 mmol. $118 \mathrm{mg}$. Mn(IIl) complex 7 (0.05 mmol. $118 \mathrm{mg}$ ). and benzene as a solvent. After oxygen balloon was adapted to the reaction flask. Ilushing the vessel with $O_{2}$ was undertaken by evacuation cherging procedure three times. To this was added wio syringe $\mathrm{Nabl}_{4}(1.5$ mmol. $54 \mathrm{mg})$ dissolyed in $4 \mathrm{~mL}$ ethanol over $20 \mathrm{~min}$ with stirring. After the reaction mixture was stirred for $4 \mathrm{~h}$ at $\mathrm{rt}$. it was poured into sat. $\mathrm{NH}_{4} \mathrm{Cl}$ solution and extracted with diethyl cther. The organic layer was dried concentrated and flash chromatographed to give 1-pheny 1-1-propanol (99 mg. $72 \%$ yield) as the product. 